\title{
A relevância dos "letramentos" na formação de posturas críticas frente a manipulações ideológicas
}

\author{
La relevancia de los "literacidads" en la formación de posturas críticas \\ frente a las manipulaciones ideológicas \\ The relevance of "literacy" in the formation of critical positions against \\ ideological manipulations
}

Sandro Bochenek ${ }^{1}$

\begin{abstract}
Resumo
Este artigo pretende discutir a necessidade de propiciar um ensino crítico de Língua Portuguesa que, na prática, seria proporcionar aos alunos das escolas brasileiras uma "versão forte de letramento", de acordo com Soares (2001; 2004; 2007), ou "modelo ideológico" (KLEIMAN, 1995; STREET, 2003), além de refletir a respeito da necessidade de proporcionar o domínio de práticas de variados letramentos, em especial o letramento visual, para que um projeto de emancipação social torne-se de fato efetivo. Além dos autores já mencionados, a fundamentação teórica do presente artigo recorre também a Freire (1987), Giroux (1987), Pinheiro (2013), no que tange aos aspectos relacionados ao ensino crítico, e Marshall (2003), Zanchetta Júnior (2004), Kellner (2017), entre outros autores, no que se refere ao texto jornalístico. O presente trabalho empreende pesquisa bibliográfica dos instrumentos metodológicos, além de ter como corpus a análise de charges presentes em matérias jornalísticas. Os resultados preliminares demonstram que a ideologia é inerente ao processo de ensino e que mecanismos de manipulação ideológica, ainda hoje, são veementemente utilizados pelos mais diversos meios de comunicação a serviço dos “opressores” (FREIRE, 1987).
\end{abstract}

Palavras chave: Ideologia. Letramentos. Manipulação da imprensa. Mídia.

\section{Resumen}

Este artigo pretende discutir sobre la necesidad de proporcionar una enseñanza crítica de la Lengua Portuguesa que, en la práctica, seria proporcionar a los alumnos de las escuelas brasileñas una "versión fuerte de literacidad", de acuerdo con Soares (2001; 2004; 2007), o un "modelo ideológico" (KLEIMAN, 1995; STREET, 2003), además de reflexionar a respecto de la necesidad de proporcionar el dominio de prácticas de distintos literacidads, en especial el literacidad virtual, para que un proyecto de emancipación social se torne efectivo. Además de los autores ya mencionados, la fundamentación teórica del presente artigo recorre también a Freire (1987), Giroux (1987) e Pinheiro (2013) con respecto a los aspectos relacionados a la enseñanza crítica y a Marshall (2003), Zanchetta Júnior (2004), Kellner (2017), entre otros autores, en lo que se refiere al texto periodístico. El presente trabajo realiza una investigación bibliográfica de los instrumentos metodológicos, además de tener como corpus el análisis de caricaturas presentes en materias periodísticas. Los resultados preliminares demuestran que la ideología es inherente a los procesos de enseñanza y que mecanismos de manipulación ideológica aún hoy son vehementemente utilizados por los más distintos medios de comunicación a servicio de los “opresores” (FREIRE, 1987).

Palabras clave: Ideología. Literacidads. Manipulación de la prensa. Medios de comunicación.

\footnotetext{
${ }^{1}$ Mestre em Educação pela Unesp - Universidade Estadual Paulista, Doutorando em Estudos da Linguagem pela Uel - Univerdade Estadual de Londrina, Editor Chefe da Revista Entretextos/UEL. E-mail: bochenek_s@hotmail.com.
} 


\begin{abstract}
This article intends to discuss the need to provide a critical Portuguese Language teaching, which, in practical ways, would be to provide students in Brazilian schools with a "strong version of literacy", according to Soares (2001; 2004; 2007), or "ideological model" (KLEIMAN, 1995; STREET, 2003), besides reflecting the need to provide mastery of practices in various kinds of literacies, especially the visual literacy, for a social emancipation project becomes effective indeed. In addition to the authors already mentioned, the theoretical foundation of the present article also resorts to Freire (1987), Giroux (1987) and Pinheiro (2013) as regards aspects related to critical education and Marshall (2003), Zanchetta Júnior (2004), Kellner (2017), among others authors with regard to the journalistic text. The present work undertakes bibliographical research of the methodological instruments, besides having as corpus the analysis of cartoons presented in journalistic subjects. The preliminary results show that ideology is inherent in the teaching process and that ideological manipulation mechanisms are still actively used by several means of communication in benefit of the "oppressors" (FREIRE, 1987).
\end{abstract}

Keywords: Ideology. Literacy. Manipulation from the press. Media.

\title{
1. Por um ensino crítico da Língua Portuguesa
}

Muitas pesquisas já foram feitas e muitas estão em pleno andamento voltadas a diagnosticar causas e a procurar soluções para uma melhoria constante da qualidade de ensino em Língua Portuguesa e das demais disciplinas escolares, bem como para a promoção de um ensino crítico, com o objetivo de desconstruir ideologias socialmente cristalizadas, quase naturalizadas. A recomendação por um ensino de melhor qualidade, que busque estimular o senso crítico dos alunos, está presente, inclusive, nas recomendações dos PCN'S - Parâmetros Curriculares Nacionais de Língua Portuguesa -, conforme pode ser ilustrado na seguinte passagem:

Toda educação verdadeiramente comprometida com o exercício da cidadania precisa criar condições para o desenvolvimento da capacidade de uso eficaz da linguagem que satisfaça necessidades pessoais - que podem estar relacionadas às ações efetivas do cotidiano, à transmissão e busca de informação, ao exercício da reflexão. De modo geral, os textos são produzidos, lidos e ouvidos em razão de finalidades desse tipo. Sem negar a importância dos que respondem a exigências práticas da vida diária, são os textos que favorecem a reflexão crítica e imaginativa, o exercício de formas de pensamento mais elaboradas e abstratas, os mais vitais para a plena participação numa sociedade letrada (BRASIL, 1997, p. 25).

Essa ideia pode ser ilustrada, ainda, com a seguinte passagem a respeito da escolha dos conteúdos linguísticos a serem trabalhados na escola, os quais podem representar situações férteis no sentido de proporcionar cenários estimulantes de ensino, afastando-se, desse modo, a análise de gêneros textuais variados como meros pretextos:

Há conteúdos que podem ser trabalhados em situações de reflexão sobre a língua, com o objetivo de conhecer e analisar criticamente os usos da língua como veículo de valores e preconceitos de classe, credo, gênero e etnia, explicitando, por exemplo, 
a forma tendenciosa com que certos textos tratam questões sociais e étnicas, as discriminações veiculadas por meio de campanhas de saúde, os valores e as concepções difundidos pela publicidade, etc. (BRASIL, 1997, p. 36).

De todo modo, a ideia que aqui se pretende defender, isto é, a necessidade da escola trabalhar e promover um ensino crítico de Língua Portuguesa, não abre possibilidade para o seu entendimento inverso, mas sim, quer-se chamar a atenção para a necessidade de se promover um ensino capaz de gerar alunos cada vez mais críticos, seja do ponto de vista de análise e interpretação de elementos textuais, seja para elementos gráficos e não textuais presentes tanto em jornais e revistas, como em outros gêneros textuais e discursivos.

Henry Giroux (1987), ao discutir as políticas educacionais americanas nos anos 80, atenta para a necessidade de aproximar política e pedagogia (escola), no sentido de tornar os alunos mais críticos e promover uma educação de fato emancipatória. Desse modo, quer-se aqui defender a ideia da necessidade de se extinguir um ensino meramente "transmissor" de conhecimento e legitimar a escola como um espaço próprio de promoção de críticas sociais diversas, capazes de romper com poderes dominantes e alienadores, além de promover instrumentais linguísticos capazes de auxiliar nessa empreitada. De acordo com o autor:

[...] tornar o público mais pedagógico significa utilizar formas de pedagogia que: tratem os estudantes como agentes críticos, problematizam o conhecimento, utilizem o diálogo e tornem o conhecimento mais significativo, de tal modo a fazê-lo crítico, para que seja emancipatório. Em parte, isso sugere que os intelectuais transformadores atentem seriamente para a necessidade de dar aos alunos voz ativa em suas experiências de aprendizagem; significa desenvolver um vernáculo crítico, que seja adequado aos problemas experienciados ao nível da vida diária, especialmente quando estes são relacionados com experiências pedagógicas desenvolvidas por práticas em sala de aula (GIROUX, 1987, p. 33).

O clamor por um ensino crítico e emancipatório voltado à promoção de letramento crítico não é novo. Vale ressaltar, no entanto, que, de acordo com Mortatti (2004), a palavra letramento começou a ser utilizada por pesquisadores da área, no Brasil, na década de 1980, e surgiu, segundo a autora, pela necessidade de diferenciar práticas de letramento de práticas de alfabetização, ou seja, emergiu da importância de se definir e diferenciar do que até então era tratado, de maneira até certo ponto genérica, por "alfabetização". Atualmente o termo é largamente utilizado no campo educacional e definido como os diversos usos sociais de habilidades diversas, tais como Letramento Metamidiático, por Lemke (2010), Letramento Matemático, por Galvão e Nacarato (2013), Letramento Funcional em Saúde, por Passamai et al. (2012), Letramento Digital, por Freitas (2010), Letramento Literário, por Cosson (2010), entre outros. 
Durante a ditadura militar, Paulo Freire já apresentava a necessidade de uma formação capaz de romper com as velhas práticas de manipulação ideológica dos alunos. É o caso do livro Pedagogia do Oprimido, de Freire (1987), o qual ganha uma ressignificação com os últimos acontecimentos políticos no Brasil, demonstrando que velhas técnicas de manipulação midiática das massas ainda se mostram eficazes em países cujo ensino é pensado pelas elites dominantes opressoras, com o objetivo apenas de manter seus próprios privilégios em detrimento dos mínimos direitos de uma maioria oprimida.

Como auxiliar desta ação divisória, encontramos nela uma certa conotação messiânica, através da qual os dominadores pretendem aparecer como salvadores dos homens a quem desumanizam. No fundo, porém, o messianismo contido na sua ação não pode esconder o seu intento. O que eles querem é salvar-se a si mesmos. É salvar sua riqueza, seu poder, seu estilo de vida, com que esmagam aos demais (FREIRE, 1987, p. 82).

Desse modo, pode-se ilustrar as ideias defendidas por Freire (1987) ao se analisarem os já evidentes objetivos do golpe brasileiro de 2016: reduzir os direitos sociais - a exemplo da proposta de reforma da Previdência, com maior contribuição no tempo de aposentadoria e preservar os privilégios de determinados grupos socialmente favorecidos. Desse modo, percebe-se que a construção de ideias messiânicas ainda são mecanismos eficientes de convencimento das massas no que tange a interesses políticos diversos; todavia, uma vez postas em prática, percebe-se que esses ideais exercem forças opostas, principalmente aos interesses das classes populares e socialmente menos favorecidas.

Outro aspecto descrito por Freire e utilizado recentemente no Brasil é o da manipulação exercida pelos meios de comunicação de massa, principalmente pela televisão em especial a Rede Globo - como se pode exemplificar citando a manchete divulgada em 21/02/2015: "Com dólar nas alturas, brasileiro perde poder de compra e evita exterior" (G1, 2015), dentre muitas outras de igual teor, as quais foram divulgadas de modo a criar uma imagem negativa frente à alta do dólar; e com a manchete de 15/05/2016: "Dólar alto deixa Brasil 'barato' para estrangeiros e atrai turistas" (G1, 2016), divulgada após o golpe, a qual tem por objetivo criar uma imagem oposta relacionada ao mesmo fato. A manipulação exercida por esses meios de comunicação refere-se ao modo como as notícias são construídas, sempre tendenciosas, de modo a criar determinada "verdade" a respeito de uma notícia, além da amenização - ou total omissão - de notícias negativas relacionadas a determinados grupos de interesses políticos próximos ao do próprio meio de comunicação que as divulga, o que descaracteriza por completo a função social da imprensa e do compromisso com a verdade, 
tendo em vista que esta - a verdade - não tem apenas um lado, mas é multifacetada e a exploração de um deles atende a conveniências cujos fins são estranhos ao interesse popular.

Todavia, em virtude da pouca - ou nenhuma - formação política das grandes massas, essas estratégias de manipulação exercem fortes efeitos na população de maneira bastante abrangente:

Através da manipulação, as elites dominadoras vão tentando conformar as massas populares a seus objetivos. E, quanto mais imaturas, politicamente, estejam elas (rurais ou urbanas) tanto mais facilmente se deixam manipular pelas elites dominadoras que não podem querer que se esgote seu poder (FREIRE, 1987, p. 83).

Além disso, Freire (1987) aponta que, travestidos de notícias, os meios de comunicação de massa desempenham papel fundamental na divulgação de determinadas ideologias de modo a criar "mitos" junto às classes populares, comungados por grandes parcelas da sociedade, as quais utilizam a televisão como única fonte de informação:

O mito, por exemplo, de que a ordem opressora é uma ordem de liberdade. De que todos são livres para trabalhar onde queiram. Se não lhes agrada o patrão, podem então deixá-la e procurar outro emprego. O mito de que esta "ordem" respeita os direitos da pessoa humana e que, portanto, é digna de todo apreço. [...] O mito do direito de todos à educação, quando o número de brasileiros que chegam às escolas primárias do país e o do que nelas conseguem permanecer é chocantemente irrisório. [...] Todos estes mitos e mais outros que o leitor poderá acrescentar, cuja introjeção pelas massas populares oprimidas é básica para a sua conquista, são levados a elas pela propaganda bem organizada, pelos slogans, cujos veículos são sempre os chamados "meios de comunicação com as massas". Como se o depósito deste conteúdo alienante nelas fosse realmente comunicação (FREIRE, 1987, p. 79).

Vale salientar que, embora Paulo Freire não tenha utilizado em seus estudos o termo "letramento", pois o autor é contemporâneo a utilização deste, a perspectiva de ensino por ele defendida durante toda a sua trajetória acadêmica vai ao encontro dessa perspectiva, o que, inclusive, tornou o autor mundialmente reconhecido. Por esse motivo se entende que a perspectiva do autor não se distancia, portanto, das perspectivas teóricas atuais do letramento. Dito de outro modo, é possível e rentável uma relação entre uma perspectiva teórica freireana e a guinada crítica de letramento aqui proposta.

Nesse sentido, Leandro Marshall (2003) salienta que os meios de comunicação e o jornalismo estão a serviço das classes dominantes, de modo a servir como mecanismos de dominação ideológica, de construção de "verdades" e de alienação, e buscam a adesão de grandes massas a favor de seus próprios interesses. 
A Teoria Crítica tem demonstrado que o jornalismo é palco do processo de dominação social e de luta de classes. A classe capitalista, detentora do poder na sociedade, usa o jornalismo como mais um recurso para seus interesses utilizando as massas como fonte de consumo, audiência, manipulação, sujeição e exploração (MARSHALL, 2003, p. 51).

Desse modo, pode-se dizer que a promoção de um ensino crítico visa romper com a prática bancária de educação - para utilizar um termo freireano -, na qual o professor é considerado o único detentor de conhecimento e os alunos meros depositários do saber. De acordo com o mestre, o conhecimento de mundo dos educandos precisa ser respeitado e também considerado na prática docente. Hoje, com a tecnologia cada vez mais presente na sala de aula, esse conceito ganha ainda mais importância, tendo em vista que muitos alunos têm acesso a uma grande quantidade de informações em tempo real por meio dos celulares, laptops, etc. Nas palavras de Freire:

Na visão "bancária" da educação, o "saber" é uma doação dos que se julgam sábios aos que julgam nada saber. Doação que se funda numa das manifestações instrumentais da ideologia da opressão - a absolutização da ignorância, que constitui o que chamamos de alienação da ignorância, segundo a qual esta se encontra sempre no outro (FREIRE, 1987, p. 33).

Outro aspecto que revela a atualidade da teoria de Freire e que comprova como "os opressores" se utilizam de diversos mecanismos de modo a dominar ideologicamente "os oprimidos" refere-se à Educação, a exemplo da proposta recente de reforma do Ensino Médio. Mesmo havendo um grande número de protestos de estudantes e educadores, além de críticas de especialistas da área de Educação, o governo levou a referida reforma adiante, a qual tem por objetivo - dentre outros absurdos - reestabelecer uma educação contrária ao desenvolvimento do ensino crítico - por meio da eliminação de disciplinas como Filosofia e Sociologia, que perdem seu caráter obrigatório - e mais voltada para uma formação profissional. A grande crítica que se faz, nesse sentido, refere-se ao fato de que, desse modo, o ensino passa a ser direcionado conforme "classes sociais", passando a "formar" mão de obra aligeirada para suprir as necessidades do mercado e deixando, ao mesmo tempo, o Ensino Superior voltado para a formação das elites:

A pedagogia, assim, é reduzida à implementação de taxionomias que subordinam o conhecimento a formas de reificação metodológica, enquanto as teorias de ensino tornam-se cada vez mais técnicas e padronizadas, no interesse da eficiência, do gerenciamento e do controle de formas limitadas de conhecimento (GIROUX, 1987, p. 9). 
Um ensino voltado à formação crítica do aluno, conforme aqui se quer defender, se de fato implementado, promoveria o que Magda Soares (2001, 2004, 2007) chama de "versão forte de letramento", ou Angela Kleiman (1995) e Brian Street (2003) chamam de "modelo ideológico". Essas concepções defendem que, se assim praticado, o ensino de língua materna seria capaz de promover uma profunda crítica social, capaz de romper com dominações ideológicas e questionar injustiças sociais. Soares (2001, p. 78) destaca que:

[...] os conceitos de letramento que enfatizam sua dimensão social fundamentam-se ou em seu valor pragmático, isto é, na necessidade de letramento para efetivo funcionamento da sociedade (a versão "fraca"), ou em seu poder "revolucionário", ou seja, em seu potencial para transformar relações e práticas sociais injustas (a versão "forte").

Infelizmente, o ensino no Brasil, seja público ou privado, por razões que vão desde a má formação de professores a políticas governamentais e de regulação dos currículos escolares, está longe de promover tais práticas de ensino. Porém, acredita-se que se o objetivo for o de conquistar justiça social no futuro, a busca por tais modalidades deverá ser traçada nos moldes de ensino hoje, na esperança de que gerações futuras tenham maior senso crítico sobre a própria realidade, mesmo que isso signifique, ao professor, enfrentar seus próprios medos.

Caso o professor opte por rejeitar a tensão do ensino não neutro, mas sim questionador de ideologias, poderá, inclusive, ter suas escolhas curriculares determinadas por ideologias dominantes e de controles diversos, conforme argumentam Anne Gregory e Mary Ann Cahill (2009, p. 8):

\begin{abstract}
Such acceptance of current and dominant ideologies may be motivated by fear. It may be a fear of the unknown; it may be a fear of reprisals from those in positions of power. Whatever the source of this fear, when we reject the tension, we are allowing it to drive the curricular choices we make. Curriculum, in this instance, can no longer provide a learner with the opportunity for envisioning the possible (Vasquez, 2001). Through this rejection of tension we are, in fact, manipulating our student's construction of subjectivity or "the ways in which a person gives meaning to themselves, others and the world" (Davies \& Banks, 1992, p. 2). ${ }^{2}$
\end{abstract}

\footnotetext{
${ }^{2}$ Tal aceitação das ideologias atuais e dominantes pode ser motivada pelo medo. Pode ser um medo do desconhecido; pode ser um medo de represálias daqueles em posições de poder. Seja qual for a fonte desse medo, quando rejeitamos a tensão, estamos permitindo que ela conduza as escolhas curriculares que fazemos. $\mathrm{O}$ currículo, neste caso, não pode mais fornecer ao aprendiz a oportunidade de visualizar o possível (Vasquez, 2001). Por meio dessa rejeição de tensão, estamos, de fato, manipulando a construção de subjetividade de nossos alunos ou "as maneiras pelas quais uma pessoa dá significado a si mesma, aos outros e ao mundo" (Davies \& Banks, 1992, p. 2). [Tradução nossa].
} 
De modo geral, o que aqui se pretende defender é a necessidade de um ensino crítico voltado à promoção de práticas de letramentos diversos, que tenham em vista romper com uma esfera de poder constituída e altamente articulada com diversos atores sociais - tais como o governo, os grandes setores empresariais e a mídia de modo geral - cujo objetivo é manter os privilégios de determinados grupos ao passo que escraviza, física e intelectualmente, as grandes massas, mantendo-as ideologicamente alienadas. Acredita-se que esse seja o verdadeiro papel da escola, ou seja, promover além de uma escolarização voltada ao mercado, mas um nível de letramento capaz de realmente tornar o aluno sujeito de sua própria história no exercício pleno de sua cidadania.

\section{Letramento Visual}

Para que a busca por uma melhoria da qualidade de ensino seja possível e para que de fato a escola possa promover aos alunos, de modo geral, o alcance a uma "versão forte" de letramento (SOARES, 2001; 2004; 2007) ou trabalhar conforme os sentidos socioculturais da comunidade atendida pela escola, ou seja, o "modelo ideológico" de letramento segundo Street (2014), faz-se necessário, ainda, que o domínio de outros letramentos seja promovido pelos professores, de modo a instrumentalizar os alunos na leitura plena de todos os elementos verbais e não verbais presentes em reportagens, artigos, etc.

Desse modo, Regina Pinheiro (2013) reflete acerca da atual condição brasileira comparada a sociedades cuja presença de tecnologias mostra-se mais evidente e argumenta, ainda, sobre a necessidade de se ampliar a gama de elementos de outras formas de linguagem para que uma leitura ocorra de forma "plena", conforme abaixo:

\footnotetext{
As sociedades mais tecnologizadas, em que o nível educacional dos indivíduos não se apresenta tão baixo quanto no Brasil, concebem o letramento como um fenômeno mais amplo. Nesta perspectiva, o termo se pluraliza e adquire forma de representação de sentidos, que pode ser expressa através de sentimentos, ideias e pensamentos, veiculados numa representação pública, através de conceitos visuais, auditivos, sinestésicos, olfativos, gustativos, táteis e intuitivos. Sendo assim, o conceito de letramento não se restringe à escrita; admite, portanto, outras formas de linguagem [...] (PINHEIRO, 2013, p. 33).
}

Assim, o domínio de um nível de "Letramento Visual" é algo que também deve ser trabalhado nas escolas, as quais frequentemente detêm-se apenas na análise de elementos textuais discursivos. Letramento Visual é definido por Semalli (2001), citado em Pinheiro (2013, p. 114), como “múltiplas habilidades de ler, ver, compreender, avaliar e interpretar os 
textos visuais, incluindo artefatos, imagens, desenhos ou pinturas que representam um evento, uma ideia ou emoção". Nesse sentido, evidencia-se que a capacidade de leitura também de elementos não visuais que compõem, especialmente, artigos de opinião e diversas reportagens jornalísticas, é algo essencial para que, de fato, as opiniões que se quer transmitir sejam captadas.

Marshall (2003) analisa que a presença de imagens nos jornais, bem como na imprensa de modo geral, segue ainda uma lógica mercadológica, objetivando atrair e seduzir leitores, frente a outros meios de comunicação. Nas palavras do autor:

\begin{abstract}
Outro fator decisivo para a imprensa hoje é a imagem. A concorrência entre o mundo impresso e audiovisual (que seduz os jovens e abocanha o grosso da publicidade) leva a imprensa de modo geral a adotar a linguagem audiovisual. $\mathrm{O}$ jornal impresso transforma-se em nossa época em um festival de signos e ícones, buscando atrair e estimular a atenção dos consumidores. A técnica é simples: quanto mais o jornal for parecido com um videoclipe, maior a eficácia do produto (MARSHALL, 2003, p. 49).
\end{abstract}

Esse aspecto mercadológico, inerente e cristalinamente descrito nas palavras de Marshall, não pode ser ignorado nas escolas, até porque se acredita que reconhecer a opinião presente nas imagens, bem como "propagandas" disfarçadas de notícias, também requer grau satisfatório de letramento visual.

Além disso, como assevera Kellner (2017), a presença de imagens na sociedade moderna tem sido crescentemente acompanhada de um declínio do raciocínio lógico/analítico, o que demonstra a urgente necessidade de a escola passar a considerar tais aspectos no que tange aos currículos, tendo em vista que há uma preocupação, sobretudo educacional, inerente.

[...] acompanhando a nova cultura da imagem, há um declínio dramático na taxa de alfabetização, uma perda das habilidades associadas com a argumentação racional, o pensamento linear e analítico e o discurso crítico e público. Em particular, esta mudança no alfabetismo e na consciência levou a uma degeneração do discurso público e uma perda da racionalidade na vida pública (KELLNER, 2017, p. 105).

Desse modo, alfabetizar para ler imagens deve ser também papel da escola, com o objetivo de promover não apenas um único aspecto do letramento, mas variadas formas de reflexões, sem as quais não é possível falar em letramento pleno. Além disso, percebe-se que a escola se preocupa em demasia com a escrita, negligenciando, muitas vezes, as ilustrações e demais imagens, ignorando, desse modo, as opiniões imbrincadas nesses textos. 


\section{Letramento visual e a leitura crítica das produções de sentido no Fotojornalismo}

Fotografias, imagens, charges, tirinhas e demais ilustrações contidas nas revistas e nos jornais estão frequentemente presentes em diversas atividades escolares e também nos próprios materiais didáticos, além de figurarem também em avaliações mais abrangentes, como concursos públicos e vestibulares. Desse modo, a linguagem não verbal presente nessas diversas modalidades também carrega uma grande carga ideológica de significados e de construção de sentidos de igual importância à linguagem verbal presente nos textos. Entretanto, percebe-se que nem sempre a leitura do texto não verbal é proposta adequadamente, concedendo a ela, frequentemente, um papel secundário na produção de significados dos textos, reduzindo-a ao desempenhando ilustrativo. Desse modo, entende-se que negligenciar uma profunda interpretação dos elementos não verbais no texto é negar ao aluno um aprendizado pleno.

O professor deve mostrar que a escolha dos elementos que compõem determinada notícia, artigo, etc. não é fruto de uma escolha ingênua por parte do produtor. Além disso, a leitura de imagens requer um domínio específico de letramento visual por parte dos professores e dos alunos, objetivando proporcionar a leitura adequada das ideias que o autor pretende transmitir. Entende-se que mesmo a escolha de uma determinada cor na composição de um letreiro pode produzir significados, os quais não estão presentes no texto, mas são recuperados, ressignificados, de uma maneira ou de outra. Compreende-se, desse modo, que a apreensão ou a recuperação desses significados ocorrerá conforme for o nível de letramento do sujeito que os analisa.

A fotografia, além de ilustrar os jornais e as notícias, apresenta também um ponto de vista. A localização em que estava o fotógrafo no momento do registro da cena, a luz e os ângulos podem representar argumentos suficientes de um ou de outro ponto de vista. Segundo Moacir Gadotti (2007, p. 61), "saber ler uma foto no jornal, uma imagem, uma caricatura, é tão importante quanto saber ler o texto da reportagem. Por isso existe hoje nos jornais o editor de fotos". A edição e a manipulação de fotos tornaram-se algo frequente nos jornais e revistas e um importante recurso utilizado na produção de sentidos em matérias relacionadas à política: por meio da manipulação de imagens, produz-se a valorização de determinadas figuras políticas - a exemplo do modo como a Revista Veja retrata positivamente políticos de partidos situacionistas (como PSDB, PMDB - atual MDB, etc.) ou figuras como o Juiz Sérgio Moro -; ou produz imagens nas quais políticos de oposição ao atual governo são retratados quase como uma transfiguração do próprio diabo - a exemplo das imagens do Lula na capa da 
Revista Veja , na qual o ex-presidente é retratado como um "exu do mal", cujo título da capa é: "O desespero da jararaca" (VEJA, 2016) -; ou as imagens presentes na revista Isto é , na qual uma foto da ex-presidenta Dilma Rousseff - tirada em um ato de comemoração de um gol da seleção brasileira de futebol durante a Copa do Mundo que ocorria no Brasil - é manipulada de modo a parecer uma pessoa desequilibrada, o que se harmoniza com o título da matéria: “As explosões nervosas da presidente” (ISTO É, 2016).

Desse modo, percebe-se que o domínio do letramento visual é tão importante quanto o domínio do letramento dos textos escritos verbais, tendo em vista que em um país como o Brasil, no qual o número de leitores é menor quando comparado a países desenvolvidos tendo em vista que uma hipótese possível é que não há familiaridade com os textos escritos porque nossa cultura é de tradição oral - a leitura apenas das manchetes e das fotografias é algo frequentemente praticado, o que facilita a manipulação de grandes massas a favor de políticas antissociais e antidemocráticas, além de políticas voltadas a golpes de estado, como os praticados em países latino-americanos na última década, a exemplo da Venezuela, do Paraguai e, mais recentemente, do Brasil. Em termos gerais, pode-se dizer que a fotografia jornalística apresenta-se tão (ou mais) importante que o título da matéria, com a função de, como no caso do título, atrair o leitor para o texto escrito. Mas a fotografia pode ter seu próprio ponto de vista em relação a determinado fato, por vezes, contradizendo até mesmo o que está escrito no texto ou indo além do que está informado por meio das palavras.

A manipulação de imagens pode ser exercida também com o objetivo de torná-las mais atraentes aos leitores, o que é também bastante presente nos jornais, nas revistas e em noticiários atuais. Essa também é uma das características das teorias pós-modernistas, de seduzir o público pelas imagens e pelas aparências, conforme Santos (2004). Assim, além das condições naturais das fotos, há situações de alteração de imagens que também são utilizadas nos expedientes jornalísticos de forma a produzir determinado efeito. Nesse sentido, Zanchetta Júnior (2004, p. 82) alerta:

Muitas vezes despercebidos, mesmo por que o que se publica é o produto final do processo fotográfico, eles viabilizam a fotografia, condicionam sua qualidade e também possibilitam a adulteração da imagem (antes, por ação mecânica; hoje em dia, por meios eletrônicos). [...] Atualmente, em que elas são processadas eletronicamente, é possível apagar, acrescentar, mudar de posição, escurecer e clarear elementos em uma fotografia praticamente sem deixar vestígio físico. 
Desse modo, nota-se que o letramento visual oferece capacidade para determinar se uma fotografia foi ou não manipulada, mas também abrange a capacidade para ler o que determinada imagem quer dizer na notícia/reportagem/matéria.

Ainda nessa perspectiva, Elcias Lustosa (1996) apresenta a concepção da teoria crítica a respeito das fotografias jornalísticas:

Na perspectiva da teoria crítica, os veículos de comunicação criam necessidades, ou seja, produzem a idéia de que alguns bens são necessários ou atendem a necessidades. [...] Na visão pós-moderna, o veículo de comunicação de massa exerce um papel mais radical na medida em que ele recria a realidade/o real, de forma mais atraente e sedutora. O simulacro é uma reconstrução do real, transformando-o em uma nova realidade, mais intensa do que a original (LUSTOSA, 1996, p. 28).

As fotografias jornalísticas podem ou não retratar uma realidade concreta. Pode ser que essa realidade registrada na fotografia, de acordo com Lustosa (1996), tenha sido modificada por interesses diversos, como comerciais, por exemplo, de modo a "seduzir" o leitor a realizar determinado tipo de leitura de um ambiente qualquer. Santos (2004) apresenta os mesmos pontos de vista trazidos por Lustosa (1996), porém pautando a análise no meio televisivo:

\footnotetext{
Simular por imagens como na TV, que dá o mundo acontecendo, significa apagar a diferença entre o real e o imaginário, ser e aparência. Fica apenas o simulacro passando por real. Mas o simulacro, tal qual a fotografia a cores, embeleza, intensifica o real. Ele fabrica um hiper-real, espetacular, um real mais real e mais interessante que a própria realidade. [...] O ambiente pós-moderno significa basicamente isso: entre nós e o mundo estão os meios tecnológicos de comunicação, ou seja, de simulação. Eles não nos informam sobre o mundo; eles o refazem a sua maneira, hiper-realizam o mundo, transformando-o num espetáculo. Uma reportagem a cores sobre os retirantes do Nordeste deve primeiro nos seduzir e fascinar para depois nos indignar. Caso contrário, mudamos de canal. Não reagimos fora do espetáculo (SANTOS, 2004, p. 12).
}

Podem-se apresentar esses mesmos conceitos de forma resumida nas palavras de Gadotti (2007), quando relata o aspecto da angulação das fotografias, a qual pode alterar o significado de determinado fato. "O leitor deve saber que o ângulo da foto diz alguma coisa. Que a escolha das fotos não é gratuita" (GADOTTI, 2007, p. 41). O ângulo da escolha de determinada fotografia pode produzir sentidos da seguinte maneira: se a imprensa responsável por cobrir determinado protesto for politicamente favorável a este, as imagens escolhidas para ilustrar essa cobertura serão as que mostrem uma concentração da multidão, de modo que produzam o sentido de que havia um número muito grande de pessoas na passeata. Observase que, mesmo que a reportagem não deixe explícito claramente, as imagens o dirão. Se, ao 
contrário, o veículo de comunicação responsável pela cobertura for politicamente desfavorável ao protesto, as imagens escolhidas para ilustrar a matéria serão preferencialmente imagens cujos protagonistas estejam dispersos ou em situações que simulem violência, mostrando, desse modo, pouca adesão ou desaprovação popular.

Há pelo menos três abordagens distintas no tocante à forma como é percebido o fotojornalismo e como este passou a ser entendido e analisado por pesquisadores. Em uma abordagem inicial, o fotojornalismo é visto como índice de veracidade. Em um segundo momento, pesquisadores passam a considerá-lo como uma reconstrução da realidade, ou seja, como a criação de um "universo paralelo" revestido de interpretações distintas do evento que estava ocorrendo. Num terceiro momento, pesquisadores passam a entender o fotojornalismo de forma próxima a essa última abordagem, porém, considerando sempre o universo de produção da fotografia e os elementos presentes nesse momento, sem os quais não haveria a possibilidade de se construir ou mesmo de alterá-los de modo a produzir certos efeitos desejados.

E assim precisamos aprender a ler essas imagens, essas formas culturais fascinantes e sedutivas cujo impacto massivo sobre nossas vidas apenas começamos a compreender. A educação certamente deveria prestar atenção a essa nova cultura, tentando desenvolver uma pedagogia crítica que estivesse preocupada com a leitura de imagens (KELLNER, 2017, p. 105).

De todo modo, o que aqui se quer defender é que promover a leitura crítica de imagens é promover práticas de letramento tão importantes quanto quaisquer outras, tendo em vista a presença massiva de imagens atualmente. Além disso, em virtude da importância social das imagens, torna-se esse também um dos papeis da escola contemporânea.

\section{Análise de elementos não verbais presentes nos textos}

A análise de imagens e charges presentes nos jornais demanda um tipo específico de letramento - nesse caso, o visual - por parte do leitor, de modo que este possa efetivamente captar o real sentido que se pretende estabelecer. As charges abaixo foram selecionadas entre as publicadas nos jornais entre os meses de abril e junho de 2015, cenário político esse em que entravam em pauta discussões de grande relevância social, como a redução da maioridade penal e a privatização de prisões e pretendeu-se analisar como essas leituras estavam sendo feitas pela mídia. Desse modo, acredita-se que as charges selecionadas demonstram que podem ser trabalhadas na escola, preferencialmente no Ensino Médio, objetivando uma leitura 
crítica, mostrando que há pontos de vista expressos nas imagens e que a presença destas nos textos não é fruto de uma escolha "ingênua" por parte de seu produtor, mas fruto de uma elaborada concepção de valores e julgamentos a respeito do ponto de vista que se quer transmitir.

A charge presente na Figura 1 apresenta elementos verbais e não verbais. Os elementos verbais se resumem à frase que diz: "A redução da maioridade penal reduz a criminalidade!!”. Os elementos gráficos que compõem a imagem são formados pela composição de um suposto político, provavelmente um deputado federal, e isso pode ser inferido pela vestimenta típica de políticos brasileiros, o terno e a gravata, além da presença do Palácio do Planalto reproduzido ao fundo. A boca do político retratada pelo chargista simula um sorriso típico, sendo um misto de sarcasmo e deboche. O elemento mais significativo da imagem, porém, é formado por um recurso de intertextualidade usado pelo autor ao desenhar o nariz comprido e de madeira que compõe o político, o qual faz referência ao célebre boneco de madeira Pinóquio das histórias infantis, cujo nariz crescia a cada mentira contada. Desse modo, percebe-se que, para fazer uma leitura dessa imagem de maneira plena, é necessário que o leitor possua pelo menos dois tipos específicos de letramento: o letramento literário, ao reconhecer a história infantil e fazer relação com os elementos presentes na imagem, e o letramento visual, ao analisar e "decodificar" o que cada um dos elementos se propõe a representar.

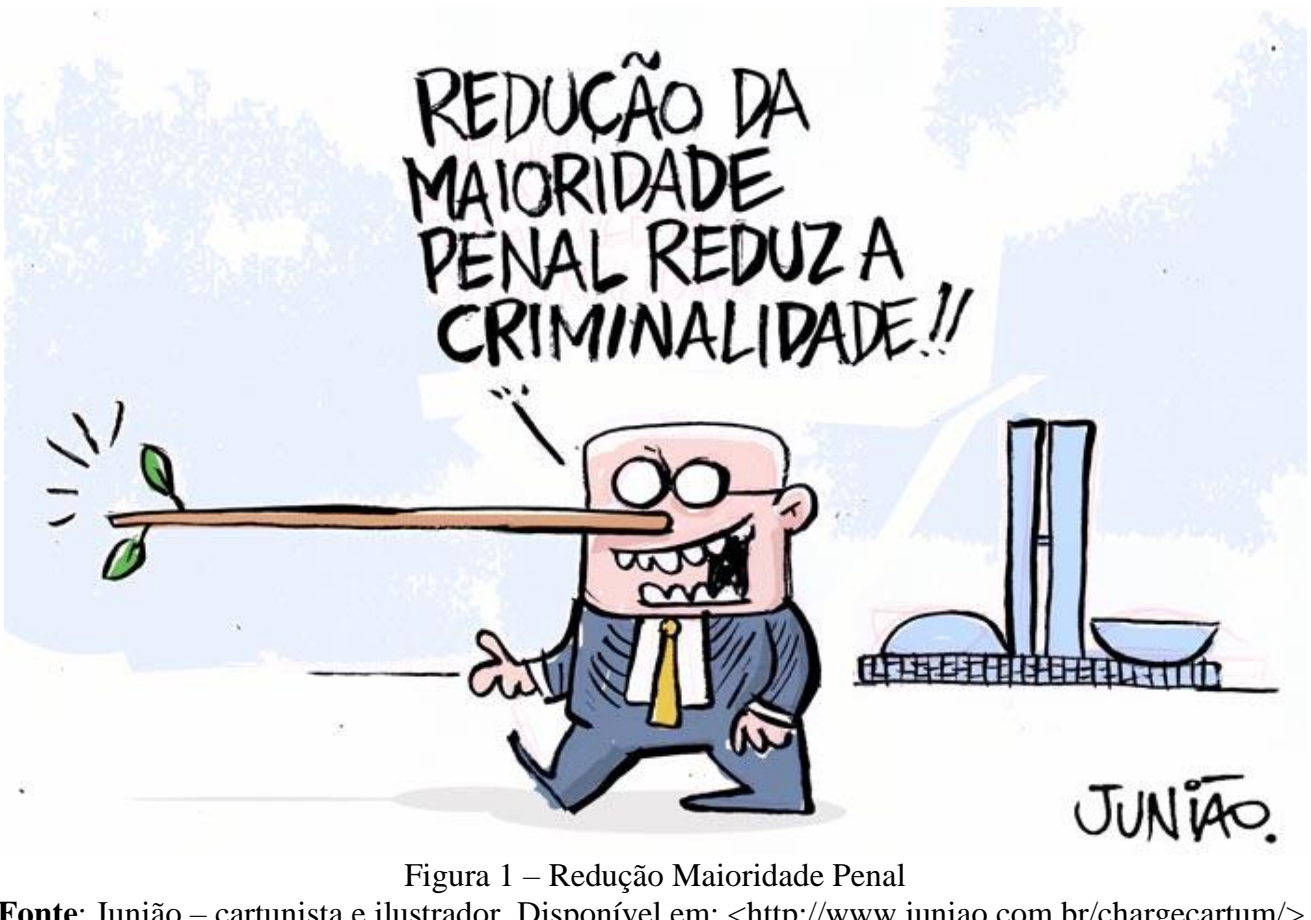


O aspecto interessante a ser analisado refere-se à desconstrução da afirmação feita por parte do político, mostrando que, embora tenha uma afirmação positiva, esta não corresponde à verdade, tendo em vista a relação que o produtor da charge procurou construir.

A Figura 2 também combina elementos verbais e elementos não verbais. Os elementos verbais são compostos pelos seguintes textos proferidos, supostamente, por pessoas anônimas: "Somos a favor da redução da maioridade penal", "Direitos humanos para humanos direitos" e "Cadeia! Cadeia neles!" e os seguintes textos, proferidos por supostos políticos em virtude da vestimenta característica: "Próximo passo: convencer essa galera que a solução para prisões superlotadas são as prisões privadas!!” e a resposta proferida pelo outro político retratado: "Yes".

Os elementos gráficos do texto são as pessoas retratadas como se não raciocinassem adequadamente e simulam uma espécie de transe, o que fica mais evidente nas três pessoas desenhadas com as mãos para frente. Pode-se dizer que os elementos gráficos, cujo retrato tende a demonstrar "o povo", fazem referência a "zumbis", presentes em muitas séries de televisão de grande sucesso no mundo inteiro, cuja composição é formada por humanos que têm como único objetivo atacar outros humanos, sem fazer a menor reflexão sobre isso. Os outros dois elementos presentes na imagem são compostos pela caricatura de dois políticos, a inferir pelos trajes usados, terno e gravata, e pelos olhos retratados como cifrões, o que remete ao lucro vislumbrado pelo pensamento de senso comum repetido pelo "povo/zumbi".
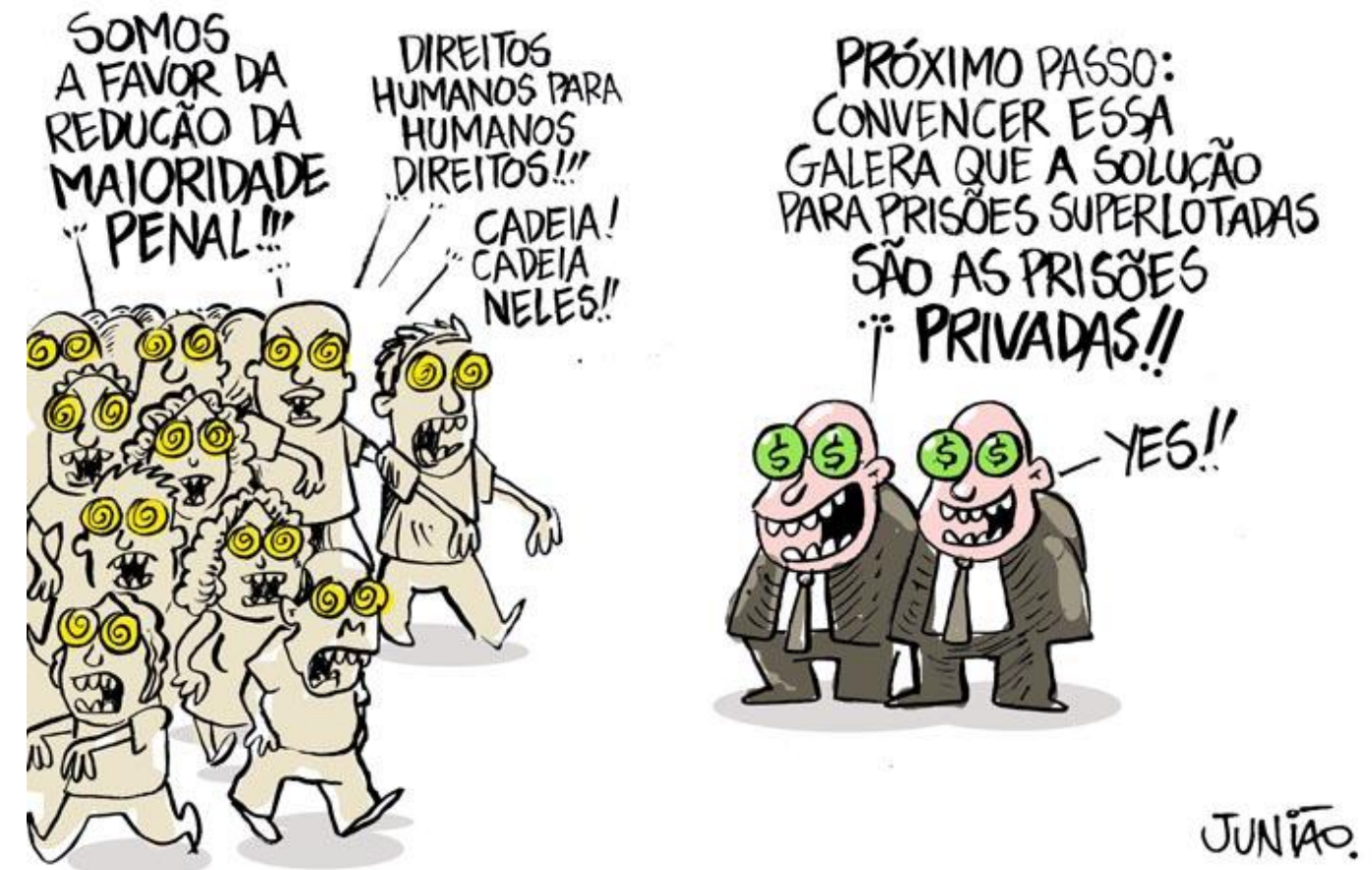

Figura 2 - Redução da Maioridade Penal 2

Fonte: Junião - cartunista e ilustrador. Disponível em: 〈http://www.juniao.com.br/chargecartum/〉. 
Pode-se dizer que a leitura da presente imagem mostra que a interpretação correta dela vai além da mera "decodificação" dos elementos verbais e não verbais, mas se refere também ao convencimento exercido por muitos veículos da imprensa, aliados a partidos políticos, os quais frequentemente manipulam e convencem as grandes massas para se posicionarem a favor de opiniões/interesses de determinados grupos políticos/econômicos.

A Figura 3 apresenta apenas elementos gráficos, o que não impede, porém, a construção de uma opinião por parte do produtor da imagem. A charge é composta por uma caricatura do Congresso Nacional, em Brasília, por um chapéu colocado sobre o Congresso, um rosário ao centro e uma espingarda pendurada na lateral do prédio. A leitura da imagem permite revelar uma crítica a respeito da composição da atual Câmara dos Deputados federais, a qual é composta basicamente por fazendeiros, representados pelo chapéu; por membros de diferentes segmentos religiosos - na grande maioria evangélicos -, representados pelo rosário; e por membros ligados a facções criminosas, representados pela presença da espingarda. A crítica que se pretende estabelecer com a presente charge revela que a composição da atual Câmara dos Deputados brasileira, com representantes eleitos do povo, não representa exatamente os interesses do povo, mas sim interesses de determinados grupos e segmentos específicos da sociedade.

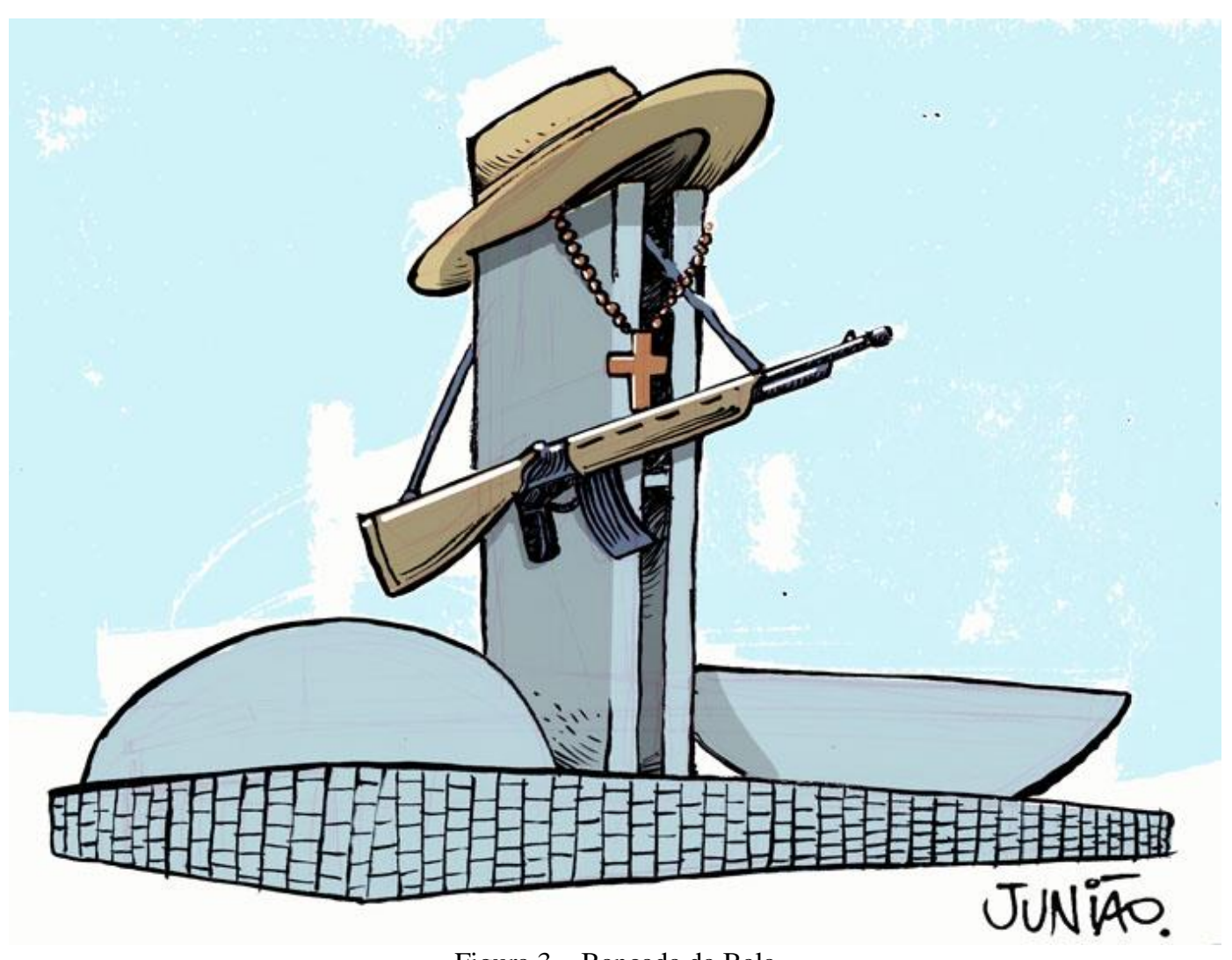

Fonte: Junião - cartunista e ilustrador. Disponível em: <http://www.juniao.com.br/chargecartum/>. 
A leitura da imagem revela que é necessário um grau compatível de letramento visual para a decodificação de opiniões presentes nela, porém, relacionando-as com fatos presentes na atual composição política brasileira. Percebe-se, em resumo, que a charge foge à mera ilustração de uma matéria jornalística relacionada à política e que a ausência de texto verbal não prejudica a transmissão de forte opinião e crítica sobre o cenário político atual, uma vez que uma grande quantidade de múltiplos sentidos é produzida, utilizando-se de elementos discursivos semióticos não verbais (FAIRCLOUGH, 1989).

Em resumo, percebe-se, desse modo, que a leitura ou mera decodificação do texto verbal não caracteriza uma leitura eficaz, uma vez que, conforme demonstrado na Figura 1, o texto contradiz a ideia que a charge quer construir. Portanto, é papel da escola contemporânea instrumentalizar os alunos para uma leitura eficiente de todos os elementos presentes nos textos, tendo em vista a crescente exploração social de elementos gráficos diversos.

\section{Considerações finais}

Procurou-se demonstrar com o presente trabalho a necessidade de se proporcionar uma abordagem de ensino que possibilite tornar os alunos mais socialmente críticos e mais conscientes sobre as artimanhas utilizadas pelos "opressores" para manter os "oprimidos" (FREIRE, 1987) em situação socialmente desfavorecida e sobre o papel da imprensa, mais especificamente do jornalismo, enquanto um dos instrumentos utilizados para manipular as massas a construir determinadas verdades sobre os fatos.

Procurou-se, ainda, demonstrar que uma modalidade de ensino que tenha por preocupação elevar o senso crítico dos alunos estará proporcionando o que Soares (2001; 2004; 2007) chama de "versão forte de letramento", ou o que Kleiman (1995) e Street (2003) chamam de "modelo ideológico", modalidade que entende o uso social da escrita como instrumento capaz de proporcionar reflexões profundas e mudanças sociais, além da necessidade da escola proporcionar aos alunos a aquisição ou o aperfeiçoamento de outros letramentos, como o visual, por exemplo, aqui analisado, que desempenham função primordial na leitura de imagens e outros elementos não verbais presentes em jornais, revistas, etc.

Por fim, procurou-se evidenciar o entendimento de que a promoção de ensino crítico faz-se necessária no sentido de perceber a importância das leituras, sejam elas de elementos verbais ou não verbais, como instrumentos capazes de promover justiça social. 


\section{Referências}

BRASIL. Secretaria de Educação Fundamental. Parâmetros curriculares nacionais: língua portuguesa / Secretaria de Educação Fundamental. - Brasília: 1997, 144p.

COSSON, Rildo. Letramento literário: teoria e prática. Editora Contexto, 2010.

FAIRCLOUGH, N. Language and power. New York, USA: Longman, 1989.

FREIRE, P. Pedagogia do Oprimido. Rio de Janeiro, RJ: Paz e Terra, 1987.

FREITAS, M. T. Letramento digital e formação de professores. Educação em Revista, 2010.

G1. Com dólar nas alturas, brasileiro perde poder de compra e evita exterior. Disponível em:

$<$ http://g1.globo.com/turismo-e-viagem/noticia/2015/02/com-dolar-nas-alturas-brasileiroperde-poder-de-compra-e-evita-exterior.html $>$.

G1. Dólar alto deixa Brasil 'barato' para estrangeiros e atrai turistas. Disponível em:

$<$ http://g1.globo.com/economia/noticia/2016/05/dolar-alto-deixa-brasil-barato-paraestrangeiros-e-atrai-turistas.html $>$.

GADOTTI, M. O Jornal na Escola e a Formação de Leitores. Brasília, DF: Líber, 2007.

GALVÃO, E. S.; NACARATO, A. M. O letramento matemático e a resolução de problemas na Provinha Brasil. Revista Eletrônica de Educação, v. 7, n. 3, p. 81-96, 2013.

GIROUX, H. Escola Crítica e Política Cultural. São Paulo, SP: Cortez, 1987.

GREGORY, A; CAHILL, M. A. Constructing critical literacy: Self-reflexive ways for curriculum and pedagogy. Critical literacy: Theories and practices, vol. 3, n. 2, p. 6-16, 2009. Disponível em:

$<$ http://criticalliteracy.freehostia.com/index.php?journal=criticalliteracy\&page=article \&op $=v i$ ewArticle\&path\%5B\%5D=35>. Acesso em: 07 jan. 2018.

ISTO É. São Paulo. $n .^{\circ} 2417.06$ abr. 2016.

JUNIÃO. Sim, existe uma bancada da bala (ponte jornalismo). 16/04/2015. Disponível em: <http://www.juniao.com.br/sim-existe-uma-bancada-da-bala-ponte-jornalismo/>. Acesso em: 07 mai. 2018.

. Mentiras sobre a redução da maioridade penal. 26/06/2015. Disponível em:

<http://www.juniao.com.br/mentiras-sobre-a-reducao-da-maioridade-penal/>. Acesso em: 07 mai. 2018.

. Quem perde e quem ganha com redução da maioridade penal. 30/06/2015. Disponível em: <http://www.juniao.com.br/quem-perde-e-quem-ganha-com-reducao-da-maioridadepenal/>. Acesso em: 07 mai. 2018. 
KELLNER, D. Lendo imagens criticamente: em direção a uma pedagogia pós-moderna. In: SILVA, T. T. da (Org.). Alienígenas na sala de aula: uma introdução aos estudos culturais em educação. Petrópolis, RJ: Vozes, 2017, p. 101-127.

KLEIMAN, Â. Modelos de letramento e as práticas de alfabetização na escola. In:

(Org.). Os significados do letramento: uma perspectiva sobre a prática social da escrita.

Campinas, SP: Mercado de Letras, 1995, p. 15-61.

LEMKE, J. L. Letramento metamidiático: transformando significados e mídias. Trabalhos em linguística Aplicada, v. 49, n. 2, p. 455-479, 2010.

LUSTOSA, E. O Texto da Notícia. Brasília, DF: UnB, 1996.

MARSHALL, L. O jornalismo na era da publicidade. São Paulo, SP: Summus, 2003.

MORTATTI, Maria do Rosário Longo. Educação e Letramento. São Paulo: UNESP, 2004.

PASSAMAI, M. P. B. et al. Letramento funcional em saúde: reflexões e conceitos sobre seu impacto na interação entre usuários, profissionais e sistema de saúde. Interface-Comunicação, Saúde, Educação, v. 16, p. 301-314, 2012.

PINHEIRO, R. C. Letramentos demandados em cursos on-line: por uma redefinição do conceito de letramentos hipertextuais. 183f. Tese (Doutorado em Linguística) - Programa de Pós-Graduação em Linguística. Universidade Federal do Ceará, Ceará, 2013. Disponível em: <http://www.repositorio.ufc.br/handle/riufc/8921>. Acesso em: 17 jan. 2017.

SANTOS, J. F. O que é Pós-Moderno. São Paulo, SP: Brasiliense, 2004.

SOARES, M. Letramento: Um Tema em Três Gêneros. Belo Horizonte, MG: Autêntica, 2001.

. Letramento e Escolarização. In: RIBEIRO, V. M. (Org.). Letramento no Brasil. São Paulo, SP: Global, 2004, p. 89-113.

. Alfabetização e Letramento. São Paulo, SP: Contexto, 2007.

STREET, B. V. Letramentos sociais-abordagens críticas do letramento no desenvolvimento, na etnografia e na educação. São Paulo: Parábola, 2014.

What's "new" in New Literacy Studies? Critical approaches to literacy in theory and practice. Current Issues in Comparative Education. v. 5, n. 2. p. 77-91, 2003. Disponível em: <https://www.tc.columbia.edu/cice/pdf/25734_5_2_Street.pdf>. Acesso em: 21 jan. 2017.

VEJA. São Paulo: Ed. Abril, ed. 2469, Ano 49, n. ${ }^{\text {1 } 11, ~} 16$ mar. 2016.

ZANCHETTA JÚNIOR, J. Imprensa Escrita e Telejornal. São Paulo, SP: UNESP, 2004. 